\title{
MY DAUGHTER LA CHOLA NEAR SONNET
}

call to me the one among your names

that opens beneath you intimate

as your next thought cymballing on the shore

arranging all those grains of sand

mica in the mosaic of the bank's portico

all your lived and storied coordinates

that you are young

that you are blank

in the air in the cluster of antennae

the remaining Barton men make of themselves riding back

the yellow fire hills of California

110

slip between understandings name

the single ridge of bell bronze that tins the wind out 